\title{
INFLUENCE OF INTERNALIZING PROBLEMS ON ACADEMIC ACHIEVEMENT IN CHINESE ADOLESCENTS: THE MEDIATING EFFECT OF ATTENTION PROBLEMS
}

\author{
Meizhen $\mathbf{L V}^{1), 2)}$, Yingjia WAN ${ }^{2)}$, and Hong $\mathbf{F U}^{2)}$ \\ 1) Department of Psychology, Peking University, China \\ 2) School of Psychology, Nanjing Normal University, China
}

\begin{abstract}
Adolescent mental health has become a public concern, and it is necessary to know how problem behaviors affect academic achievement. The current study surveyed 12,672 adolescents in eastern China, and results indicated clinical cut-offs on each problem behavior. We then examined how internalizing problems lead to negative academic results. Findings suggest Attention problems are a key factor. Anxiety/ depression and somatic complaints have no direct effect on academic performance but are mediated by attention problems. This study can serve practice of schooling and parenting, and provide basis for developing clinical intervention strategy in China.
\end{abstract}

Key words: internalizing problem, adolescent, academic achievement, attention problem, mediating effect

\section{INTRODUCTION}

\section{Problem behaviors in adolescence}

Adolescence is a critical period of physical and mental development, and also a highrisk stage of psychological conflicts, emotional problems and personality disorders. 10$20 \%$ of children and adolescents worldwide experience mental disorder. Half of all mental illnesses begin by the age of 14 and three-quarters by mid-20s (World Health Organization, 2015). It's important to study adolescent problem behaviors for knowing about their mental health and predicting their potential to live fulfilling and productive lives. In China, according to earlier rough statistics, the prevalence of problem behaviors among adolescents is $13.01 \%$ (Wang, Zhang, \& Patrick, 2005), with girls experiencing more internalizing problems and less externalizing problems than boys. Another study indicates that the incidence is increasing each year (Xin \& Zhang, 2009). However, systematic surveys of Chinese adolescent mental health are limited in recent years.

\section{Internalizing problems accompanied with attention problems}

Anxiety/depression, withdrawal and somatic complaints are internalizing problems included as variables in the Youth Self-Report (YSR; Achenbach \& Rescorla, 2001) which obtains 11- to 18-year-olds' self-ratings of specific emotional, behavioral, and social

Correspondence concerning this article should be addressed to Hong Fu, School of Psychology, Nanjing Normal University (Suiyuan campus), Nanjing, China (e-mail: fuhong@njnu.edu.cn). 
problems. Research has shown that somatic complaints are the outcome of a multifactorial process in which biological, psychological, and social factors all play a role (Beck, 2008). Anxiety and depression have moderately strong contemporaneous effects on somatic symptoms. (Janssens, Rosmalen, Ormel, Van Oort, \& Oldehinkel, 2010). Withdrawal is characterized by depression, slowness or lack of energy, and shyness.

According to the meta-analysis conducted by Polanczyk, de Lima, Horta, Biederman, and Rohde (2007), the prevalence for attention problems in children and adolescents worldwide was estimated to be $5.29 \%$. Attention problems are characterized by persistent and developmentally inappropriate levels of inattention, hyperactivity and/or impulsivity, and some of the children may be formally diagnosed with attention-deficit/hyperactivity disorder (American Psychiatric Association, 2013). Children with attention problems are less able to regulate their negative emotions (Kim \& Deater-Deckard, 2011).

Studies have found that attention problems are often accompanied by internalizing problems (13-51\%; Ollendick, Jarrett, Grills-Taquechel, Hovey, \& Wolff, 2008), and they may exacerbate the outcomes of a range of internalizing behaviors ( Litner, 2003; Deault, 2010). Costello and colleagues (2003) reported that adolescents with attention problems were two to seven times more likely to have a depressive disorder compared with other adolescents. A study by Zavadenko et al. (2011) showed that ratings by both of teachers and parents reflected markedly higher levels of sadness and anxiety among children with attention problems in comparison to those without.

\section{Prediction effects of problem behaviors on academic achievement}

Many empirical studies contributed to the prediction effects of problem behaviors on academic achievement. Researchers found that depressive symptoms affected subsequent academic achievement with the possibility of a mediating third variable (Hishinuma, Chang, McArdle, \& Hamagami, 2012). Another group of researchers showed that children with anxiety disorders reported more somatic complaints than did the non-anxious children, and the higher frequency of somatic complaints specifically predicted poorer academic performance (Hughes, Lourea-Waddell, \& Kendall, 2008). Attention problems also predict academic problems such as grade repetition and lower scores on achievement tests (Polderman, Boomsma, Bartels, Verhulst, \& Huizink, 2010).

Attention deficiencies may be not only a leading cause of poor academic functioning but also an important mediator between academic functioning and a variety of other problem behaviors that do not necessarily have direct impact on academic achievements. According to a study by Barriga et al. (2002), although withdrawal, somatic complaints, rule-breaking behavior, and aggressive behavior syndromes exhibit significant zero-order correlations with the academic achievement measures, each of these effects is mediated by attention problems. However, in another comprehensive literature addressing this issue, the mediating effect of attention problems is evident only in childhood but not in adolescence (Hinshaw, 1992). It remains open to debate whether attention problems plays a mediating role for Chinese adolescents.

This study aims to build models to clarify the mediating effect of attention problem between internalizing problems and academic achievement. As youth with attention 
problem may be at higher risk of social problems and peer difficulties (Tseng \& Gau, 2013), we further examine correlations of internalizing problems, attention problems and social problems.

\section{Materials AND Methods}

\section{Participants}

The sample was collected using stratified random sampling. It consisted of 6414 boys and 6258 girls aged from 9 to 20 years. All elementary school students in the sample were enrolled in the fifth or the sixth grades. The older students came from junior high schools, common high schools, key middle schools, selective high schools and vocational schools. Two classes were selected from each school. The sample covered 9 cities and three social economic areas in Jiangsu Province (the north, south and central JiangSu). All students and their school leaders signed the consent form.

\section{Measures}

Adolescent Mental Health Related Behavior Questionnaire. The Chinese version of this questionnaire is a multidimensional rating scale that records the demographic information, adaptive functioning and problem behaviors of the youth. It also measures the academic achievements of the youth with a self-rating scale.

Youth Self-Report. This questionnaire consists of two parts. The first part contains a series of questions assessing adaptive behavior. The second part contains 118 items rated on a three-point scale: $0=$ not true, $1=$ sometimes true, 2 = often true. The ratings of the items are combined to form eight narrow band scales or syndromes, two broad-band scales and a total problem scale. The eight syndrome scales (Withdrawal, Somatic Complaints, Anxiety/Depression, Social Problems, Thought Problems, Attention Problems, Rule-breaking Behavior, and Aggressive Behavior) consist of the YSR factor structure which is used to represent various problem behaviors. The broad-band scales consist of one internalizing scale and one externalizing scale. The internalizing scale is made up of the withdrawal, somatic complaints and anxious/depressed scales whereas the externalizing scale is made up of the aggressive behavior and rule-breaking behavior scales.

Ivanova et al. (2007) have tested the syndrome structure in 23 societies to examine the similarity. The results shows that the eight-syndrome structure fits the patterns of problem ratings by different participants in a wide range of societies and is generalizable to ages 11 to 18 years.

\section{Procedure}

The survey was conducted in a quiet, distraction-free student center by trained experimenters. Students visited a specified website to fill out the questionnaires. All the answers were entered into the project implementation unit. Structural equation modeling was based on the scores of all 12,672 participants, and multiple regression analysis was used to examine the effects of problem behavior on academic achievement.

\section{RESULTS}

\section{Descriptive statistics and cut-off scores}

Mean scores and standard deviations of both genders are presented in Table 1. An independent-samples t test for boys and girls shows that the gender effect was statistically significant on the withdrawal, social problems, thought problems, attention problems, rule breaking behavior and aggressive behavior. Girls' scores were significantly higher on internalizing problems but lower on externalizing problems than boys' scores.

Cut-off scores for the YSR were calculated according to Achenbach's suggestion of the top $2 \%$ of the narrow band scales and the top $10 \%$ of the broad band scales as the 
Table 1. Mean scores and standard deviations of YSR problem scales and Chinese cut-off scores, representing the $90^{\text {th }}$ and $98^{\text {th }}$ percentiles for 12672 adolescents aged 9 to 20 years.

\begin{tabular}{|c|c|c|c|c|c|c|c|c|c|}
\hline \multirow{2}{*}{ Problems Scales } & \multicolumn{4}{|c|}{ Boys $(\mathrm{N}=6414)$} & \multicolumn{4}{|c|}{ Girls $(N=6258)$} & \multirow{2}{*}{ Sig. } \\
\hline & Mean & $S D$ & $90 \%$ & $98 \%$ & Mean & $S D$ & $90 \%$ & $98 \%$ & \\
\hline Anxiety/Depressed & 3.833 & 4.807 & 11 & 18 & 4.463 & 4.745 & 11 & 18 & 0.196 \\
\hline Withdrawal & 2.358 & 2.774 & 6 & 10 & 2.557 & 2.614 & 6 & 9 & 0.001 \\
\hline Somatic complaints & 2.440 & 3.784 & 8 & 14 & 2.862 & 3.621 & 8 & 14 & 0.874 \\
\hline Social problems & 3.076 & 3.876 & 8 & 13 & 2.874 & 3.188 & 7 & 11 & 0.000 \\
\hline Thought problems & 3.642 & 4.612 & 10 & 17 & 3.781 & 4.230 & 10 & 16 & 0.000 \\
\hline Attention problems & 2.775 & 2.934 & 7 & 11 & 2.582 & 2.689 & 6 & 9 & 0.000 \\
\hline Rule breaking behavior & 2.206 & 3.751 & 6 & 13 & 1.625 & 2.745 & 4 & 9 & 0.000 \\
\hline Aggressive behavior & 4.372 & 5.733 & 11 & 21 & 4.154 & 4.805 & 10 & 17 & 0.000 \\
\hline Internalizing problems & 8.632 & 10.476 & 23 & 39 & 9.881 & 9.834 & 23 & 37 & 0.156 \\
\hline Externalizing problems & 6.579 & 9.173 & 17 & 32 & 5.779 & 7.150 & 13 & 26 & 0.000 \\
\hline Total problems & 28.649 & 32.988 & 70 & 115 & 24.897 & 24.731 & 56 & 89 & 0.000 \\
\hline
\end{tabular}

clinical range (Roussos et al., 2001). Table1 shows the descriptive statistics of YSR problem behavior scales and the cut-off scores for both genders.

\section{Mediation effect of attention problems}

We explored how attention problems acted as a (partial) mediator and indirectly affected academic achievement (observed variable) in our subsequent regression analysis. We used regression procedures put forward by Wen, Zhang, Hou, and Liu (2004) to reduce the likelihood of Type I and Type IIerror.

Results indicated that (see table 2) the attention problems variable was a (partial) mediator. In the first model (anxiety/depression as the independent variable) and the third model (somatic complaints as the independent variable), attention problems played a completely mediating role in the relation between problem behaviors and academic performance. The estimate of the mediating effect was -0.061 , and its relative size (the ratio of mediating effect to the total effect) was 0.813 in the first model, and the estimate of the mediating effect was -0.049 , and the relative size was 0.778 in the third model. In the second model, attention problems variable was only a partial mediator, the estimate of the mediating effect was -0.019 , and the relative size was 0.213 .

Results demonstrated that anxiety/depression and withdrawal have no direct negative impact on academic performance whereas somatic problems do.

\section{Association of problem bahaviors}

Confirmatory factor analysis (CFA) was performed. Standardized factor loadings of 
Table 2. Regression analysis of problem behaviors on academic achievement (y coded as academic achievement, $\mathrm{x}$ coded as anxiety or depression, $\mathrm{u}$ coded as withdrawal, $\mathrm{v}$ coded as somatic complaints, w coded as attention problems).

\begin{tabular}{|c|c|c|c|c|c|}
\hline \multirow{2}{*}{$\frac{\text { Model }}{1}$} & \multirow{2}{*}{$\begin{array}{c}\text { Procedures } \\
\text { Step } 1 .\end{array}$} & \multirow{2}{*}{$\begin{array}{c}\begin{array}{c}\text { Standardized regression } \\
\text { equations }\end{array} \\
\mathrm{y}=-0.075 \mathrm{x}\end{array}$} & \multicolumn{2}{|c|}{ Regression cofficients } & \multirow{2}{*}{$\begin{array}{c}R^{2} \\
0.006\end{array}$} \\
\hline & & & $\mathrm{SE}=0.009$ & $\mathrm{t}=-8.419^{* * *}$ & \\
\hline & Step 2. & $\mathrm{w}=0.537 \mathrm{x}$ & $\mathrm{SE}=0.007$ & $\mathrm{t}=71.615 * * *$ & 0.288 \\
\hline & Step 3. & $\mathrm{y}=-0.014 \mathrm{x}-0.113 \mathrm{w}$ & $\begin{array}{l}\mathrm{SE}=0.010 \\
\mathrm{SE}=0.010\end{array}$ & $\begin{array}{l}\mathrm{t}=-1.341 \\
\mathrm{t}=-10.795^{* * *}\end{array}$ & 0.015 \\
\hline \multirow[t]{3}{*}{2} & Step 1. & $\mathrm{y}=-0.071 \mathrm{u}$ & $\mathrm{SE}=0.009$ & $\mathrm{t}=-8.044 * * *$ & 0.005 \\
\hline & Step 2. & $\mathrm{w}=0.388 \mathrm{u}$ & $\mathrm{SE}=0.008$ & $\mathrm{t}=47.402 * * *$ & 0.151 \\
\hline & Step 3. & $\mathrm{y}=-0.029 \mathrm{u}-0.109 \mathrm{w}$ & $\begin{array}{l}\mathrm{SE}=0.010 \\
\mathrm{SE}=0.010\end{array}$ & $\begin{array}{l}\mathrm{t}=-3.024 * * \\
\mathrm{t}=-11.408 * * *\end{array}$ & 0.015 \\
\hline \multirow[t]{3}{*}{3} & Step 1. & $\mathrm{y}=-0.063 \mathrm{v}$ & $\mathrm{SE}=0.009$ & $\mathrm{t}=-7.125^{* * *}$ & 0.004 \\
\hline & Step 2. & $\mathrm{w}=0.432 \mathrm{v}$ & $\mathrm{SE}=0.008$ & $\mathrm{t}=53.868 * * *$ & 0.186 \\
\hline & Step 3. & $\mathrm{y}=-0.014 \mathrm{v}-0.114 \mathrm{w}$ & $\begin{array}{l}\mathrm{SE}=0.010 \\
\mathrm{SE}=0.010\end{array}$ & $\begin{array}{l}\mathrm{t}=-1.409 \\
\mathrm{t}=-11.702 * * *\end{array}$ & 0.014 \\
\hline
\end{tabular}

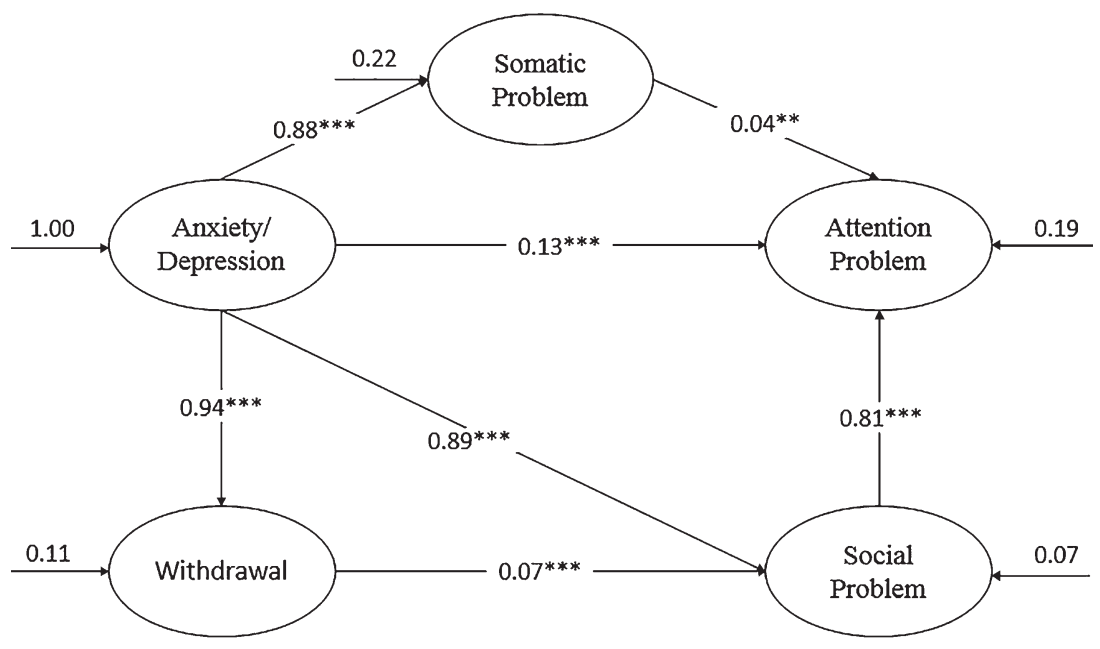

Fig. 1. Structural equation model of problem behaviors.

all data were over 0.53 . The root mean square error of approximation was 0.11 , and the comparative fit index was 0.95 (considering the size of our sample, chi-square was not used).

Fig. 1 presents the final structural equation model including standardized coefficients and the p-values. Lisrel 8.7 (Maximum Likelihood) was used for analysis. Model fit the data sufficiently $(\mathrm{NFI}=0.95, \mathrm{CFI}=0.97)$. 


\section{DISCUSSION}

\section{Adolescents' Problem behaviors in Eastern China}

The current study presents results of YSR in Eastern China. The cut-offs at the $90^{\text {th }}$ and $98^{\text {th }}$ percentile are meaningful in a variety of fields including clinical treatment and counseling. Compared with U.S. data (Achenbach, 1991), scores on all problem behaviors are lower in Chinese adolescents. Previous studies have found that Chinese/Asian children experience more internalizing problems whereas Western children experience more externalizing problems (Yang, Soong, Chiang, \& Chen, 2000; Liu et al., 2001). We found a significant gender difference on problem behaviors, with boys verifying more externalizing but fewer internalizing problems than girls.

Internalizing problems are common in Chinese children and may represent "normal" reactions to some dominant cultural forces (Liu, Cheng, \& Leung, 2011). The "problem suppression-facilitation model" (Weisz et al., 1987) considers suppressing or inhibiting the expression as one source of internalizing problems. Asian/Eastern values encourage emotional control and restraint (suppression) while American/Western values encourage free and open emotional expression ( Soto, Levenson, \& Ebling, 2005; Butler \& Gross, 2009). Suppression can be an emotion regulation strategy in China, as cultural expectations may encourage adolescents to suppress their negative emotions in social situations. However, overuse of this strategy is related to poorer adjustment (Bonanno, Papa, Lalande, Westphal, \& Coifman, 2004) and might incur internalizing problem behaviors (Hsieh \& Stright, 2012).

\section{Mediating effect of attention problems}

In this study, attention problems play a mediating role between internalizing problems and academic performance, and a partial mediating role the prediction of social problems.

Adolescents with attention problems have symptoms of impatience and low frustration tolerance, which impairs academic achievement (Biederman, 2005). Neuropsychological theories suggest biological factors in the cognitive impairments related to attention problems (Sagvolden, Johansen, Aase, \& Russell, 2005). On the other hand, cognitive impairment is heterogeneous and it can be promoted by internalizing factors (Etgen et al., 2009).

The mediating effects of attention problems in this study suggest that they present risks for academic achievement. A one-year longitudinal study in China has revealed that after controlling Time 1 internalizing problems, Time 1 academic achievement was a significant predictor of Time 2 internalizing problems. However, Time 1 internalizing problems were not a significant predictor of Time 2 academic achievement when controlling Time 1 academic achievement (Ding \& Shi, 2012), which is strongly verified in the present study.

\section{Problem behaviors in adolescents}

Structural equation modeling shows that attention problem is highly correlated with internalizing problems and social problems. Clinical reviews also show that attention problems have high comorbid rates with depression and anxiety (Angold, Costello, \& Erkanli, 1999). 
In this study, we point out two main ways of how internalizing problems and externalizing problems incur attention problems. Anxiety and depression could lead to attention problems as a partial mediating factor and result in negative effects through somatic complaints. Adolescents who are immersed in depression or stressful situations may experience psychogenic body complaints which then lead to inattentiveness or hyperactivity. Secondly, social problems could also partially mediate between depression and anxiety and attention problems. Adolescents who are depressed or anxious may fear school or feel unloved, worry about failure or worthlessness, and even generate terrible thoughts of undue guilty, inferiority and suicide. These irrational thoughts give rise to social difficulties, characterized by loneliness, clumsiness, selfishness, overdependence, envy, accident proneness, getting teased, etc. Adolescents' self-reports have also demonstrated that problems in social communication could act as a predictor.

\section{Limitations and future directions}

Several limitations should be noted in this study. Firstly, the measures of problem behaviors and academic achievement are based on self-reports, and obtained relationships could be influenced by common method variance. Secondly, socio-regional context may be a significant influential factor in adolescents' health behavior, as our sample was collected exclusively in eastern China. In China, adolescents from different regions have diverse education and growth backgrounds, so future studies should take regional differences into consideration. Thirdly, this study lacks follow-up data. The causes and effects of problem behaviors should be further studied in precise cross-sectional studies.

\section{REFERENCES}

Achenbach, T. M. 1991. Manual for the youth self-report and 1991 profile. Burlington, Department of Psychiatry, University of Vermont.

Achenbach, T. M., \& Rescorla, L. 2001. Manual for the ASEBA school-age forms \& profiles. Burlington, VT: ASEBA.

American Psychiatric Association. 2013. Diagnostic and statistical manual of mental disorders: DSM-5. Arlington, VA: Author.

Angold, A., Costello, E. J., \& Erkanli, A. 1999. Comorbidity. Journal of Child Psychology and Psychiatry, 40, 57-87.

Barriga, A. Q., Doran, J. W., Newell, S. B., Morrison, E. M., Barbetti, V., \& Robbins, B. D. 2002. Relationships between problem behaviors and academic achievement in adolescents: The unique role of attention problems. Journal of Emotional and Behavioral Disorders, 10, 233-240.

Beck, J. E. 2008. A developmental perspective on functional somatic symptoms. Journal of Pediatric Psychology, 33, 547-562.

Biederman, J. 2005. Attention-deficit/hyperactivity disorder: A selective overview. Biological Psychiatry, 57, $1215-1220$

Bonanno, G. A., Papa, A., Lalande, K., Westphal, M., \& Coifman, K. 2004. The importance of being flexible: The ability to both enhance and suppress emotional expression predicts long-term adjustment. Psychological Science, 15, 482-487.

Butler, E. A., \& Gross, J. J. 2009. Emotion and emotion regulation: Integrating individual and social levels of analysis. Emotion Review, 1, 86-87.

Costello, E. J., Mustillo, S., Erkanli, A., Keeler, G., \& Angold, A. 2003. Prevalence and development of psychiatric disorders in childhood and adolescence. Archives of General Psychiatry, 60, 837-844. 
Deault, L. C. 2010. A systematic review of parenting in relation to the development of comorbidities and functional impairments in children with attention-deficit/hyperactivity disorder (ADHD). Child Psychiatry \& Human Development, 41, 168-192.

Ding, X. C., \& Shi, X. X. 2012. Academic achievement and internalizing problem:a one-year longitudinal study. Chinese Journal of Clinical Psychology, 4, S5.

Etgen, T., Brönner, M., Sander, D., Bickel, H., Sander, K., \& Förstl, H. 2009. Somatic factors in cognitive impairment. Fortschritte der Neurologie-Psychiatrie, 77, 72-82.

Hinshaw, S. P. 1992. Externalizing behavior problems and academic underachievement in childhood and adolescence: Causal relationships and underlying mechanisms. Psychological Bulletin, 111, 127-155.

Hishinuma, E. S., Chang, J. Y., McArdle, J. J., \& Hamagami, F. 2012. Potential causal relationship between depressive symptoms and academic achievement in the Hawaiian high schools health survey using contemporary longitudinal latent variable change models. Developmental Psychology, 48, 1327-1342.

Hsieh, M., \& Stright, A. D. 2012. Adolescents' emotion regulation strategies, self-concept, and internalizing problems. The Journal of Early Adolescence, 32, 876-901.

Hughes, A. A., Lourea-Waddell, B., \& Kendall, P. C. 2008. Somatic complaints in children with anxiety disorders and their unique prediction of poorer academic performance. Child Psychiatry and Human Development, 39, 211-220.

Ivanova, M. Y., Achenbach, T. M., Rescorla, L. A., Dumenci, L., Almqvist, F., Bilenberg, N., . . Verhulst, F. C. 2007. The generalizability of the Youth Self-Report syndrome structure in 23 societies. Journal of Consulting and Clinical Psychology, 75, 729-738.

Janssens, K. A., Rosmalen, J. G., Ormel, J., Van Oort, F. V., \& Oldehinkel, A. J. 2010. Anxiety and depression are risk factors rather than consequences of functional somatic symptoms in a general population of adolescents: The TRAILS study. Journal of Child Psychology and Psychiatry, 51, 304-312.

Kim, J., \& Deater-Deckard, K. 2011. Dynamic changes in anger, externalizing and internalizing problems: Attention and regulation. Journal of Child Psychology and Psychiatry, 52, 156-166.

Litner, B. 2003. Teens with ADHD: The challenge of high school. Child and Youth Care Forum, 32, 137-158.

Liu, J., Cheng, H., \& Leung, P. W. 2011. The application of the Preschool Child Behavior Checklist and the Caregiver-Teacher Report Form to mainland Chinese children: Syndrome structure, gender differences, country effects, and inter-informant agreement. Journal of Abnormal Child Psychology, 39, 251-264.

Liu, X., Sun, Z., Neiderhiser, J. M., Uchiyama, M., Okawa, M., \& Rogan, W. 2001. Behavioral and emotional problems in Chinese adolescents: Parent and teacher reports. Journal of the American Academy of Child \& Adolescent Psychiatry, 40, 828-836.

Ollendick, T. H., Jarrett, M. A., Grills-Taquechel, A. E., Hovey, L. D., \& Wolff, J. C. 2008. Comorbidity as a predictor and moderator of treatment outcome in youth with anxiety, affective, attention deficit/ hyperactivity disorder, and oppositional/conduct disorders. Clinical Psychology Review, 28, 14471471.

Polanczyk, G., de Lima, M., Horta, B., Biederman, J., \& Rohde, L. 2007. The worldwide prevalence of ADHD: A systematic review and metaregression analysis. American Journal of Psychiatry, 164, 942948.

Polderman, T., Boomsma, D., Bartels, M., Verhulst, F., \& Huizink, A. 2010. A systematic review of prospective studies on attention problems and academic achievement. Acta Psychiatrica Scandinavica, 122, 271284.

Roussos, A., Francis, K., Zoubou, V., Kiprianos, S., Prokopiou, A., \& Richardson, C. 2001. The standardization of Achenbach's Youth Self-Report in Greece in a national sample of high school students. European Child \& Adolescent Psychiatry, 10, 47-53.

Sagvolden, T., Johansen, E. B., Aase, H., \& Russell, V. A. 2005. A dynamic developmental theory of attentiondeficit/hyperactivity disorder (ADHD) predominantly hyperactive/impulsive and combined subtypes. Behavioral and Brain Sciences, 28, 397-468.

Soto, J. A., Levenson, R. W., \& Ebling, R. 2005. Cultures of moderation and expression: Emotional experience, behavior, and physiology in Chinese Americans and Mexican Americans. Emotion, 5, 154-165.

Tseng, W. L., \& Gau, S. S. F. 2013. Executive function as a mediator in the link between attention - deficit/ hyperactivity disorder and social problems. Journal of Child Psychology and Psychiatry, 54, 9961004.

Wang, J., Zhang, Y. Q., \& Patrick, W. L. 2005. Achenbach Youth Self-Report for 12-18 years of age students 
in Beijing. Chinese Journal of Clinical Psychology, 2, 001.

Weisz, J. R., Suwanlert, S., Chaiyasit, W., Weiss, B., Achenbach, T. M., \& Walter, B. R. 1987. Epidemiology of behavioral and emotional problems among Thai and American children: Parent reports for ages 6 to 11. Journal of the American Academy of Child \& Adolescent Psychiatry, 26, 890-897.

Wen, Z., Zhang, L., Hou, J., \& Liu, H. 2004. The inspection procedures of the mediation effect and its application. Psychological Bulletin, 36, 614-620.

World Health Organization. 2015. Maternal and child mental health. Retrieved from http://www.who.int/ mental_health/maternal-child/en/

Xin, Z. Q., \& Zhang, M. 2009. Changes in Chinese middle school students' mental health (1992 2005): A cross-temporal meta-analysis. Acta Psychologica Sinica, 1, 69-78.

Yang, H. J., Soong, W. T., Chiang, C. N., \& Chen, W. J. 2000. Competence and behavioral/emotional problems among Taiwanese adolescents as reported by parents and teachers. Journal of the American Academy of Child \& Adolescent Psychiatry, 39, 232-239.

Zavadenko, N., Lebedeva, T., Schasnaya, O., Zavadenko, A., Zlobina, O., \& Semenova, N. 2011. Attention deficit hyperactivity syndrome: The role of parent and teacher questionnaires in assessing the social and psychological adaptation of patients. Neuroscience and Behavioral Physiology, 41, 52-56.

(Manuscript received 24 August, 2014; Revision accepted 5 November, 2015) 